\section{Academic libraries: An unrecognized national strength?}

\author{
By Joan Chambers
}

Member, ACRL Task Force on the White House Conference

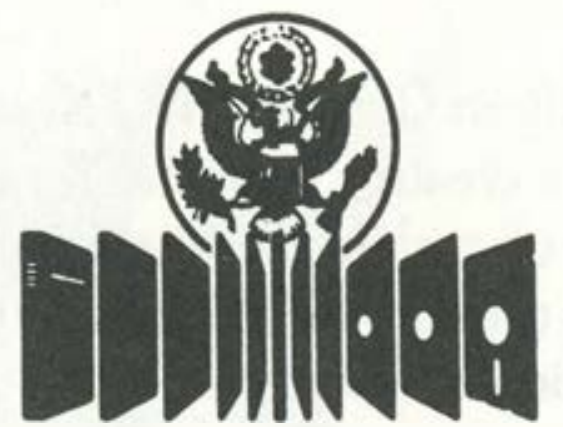

The White House Conference ON LIBRARY AND INFORMATION SERVICES 1991
As the White House Conference on Library and Information Services draws near, and as each state selects delegates and passes resolutions, to what extent will the nation's academic libraries be recognized and represented? There historically exists a broad general awareness among the populace of the roles of public and school libraries in support of an informed and educated citizenry, in promoting literacy and cultural enrichment, and in meeting the library and information needs of our increasingly diverse publics. There is, perhaps, less general awareness of the extent to which academic libraries are partners with public and school libraries in an effort to expand literacy, strengthen democracy and increase productivity.

In many cities and towns, the collections and services of a local academic library represent the most extensive library and information resources available to children and adults in the community, as well as to students. The range of academic programs served by the library generally results in collections that are broader in scope than those supported by public and school libraries. The depth of the collections required to serve the instruction and research missions of the academy also allows these collections to serve the specialized needs of entrepreneurs, businesses, industry, manufacturers, government, educators, and the professions.

The library and information needs of the public could not be met if the nearly 300 million volumes in the academic and research libraries of this country were not widely available. As the White House Conference draws near, academic librarians are encouraged to participate in their local and state conferences to ensure a broad understanding of the extensive use made of academic libraries by those outside of the academy - use that supports both basic and applied research being conducted outside of the academy.

One indication of the magnitude of the wide dependence on academic libraries is the enormous volume of interlibrary lending supported by those libraries. While some of this activity is between and among colleges and universities, the greatest portion of the more than 3 million items loaned annually goes to non-academic libraries. It is not unusual for the online catalogs of academic libraries to be freely available on local and state networks, as well as on Internet. One reason for including school and public libraries in planning for NREN, the National Research and Education Network, is to ensure their access to the rich resources available in academic libraries. This nation cannot afford academic libraries that are either an unknown or an untapped resource. Academic libraries, because of the vital contribution they make by sharing their resources, must have an explicit place in the White House Conference on Library and Information Services.

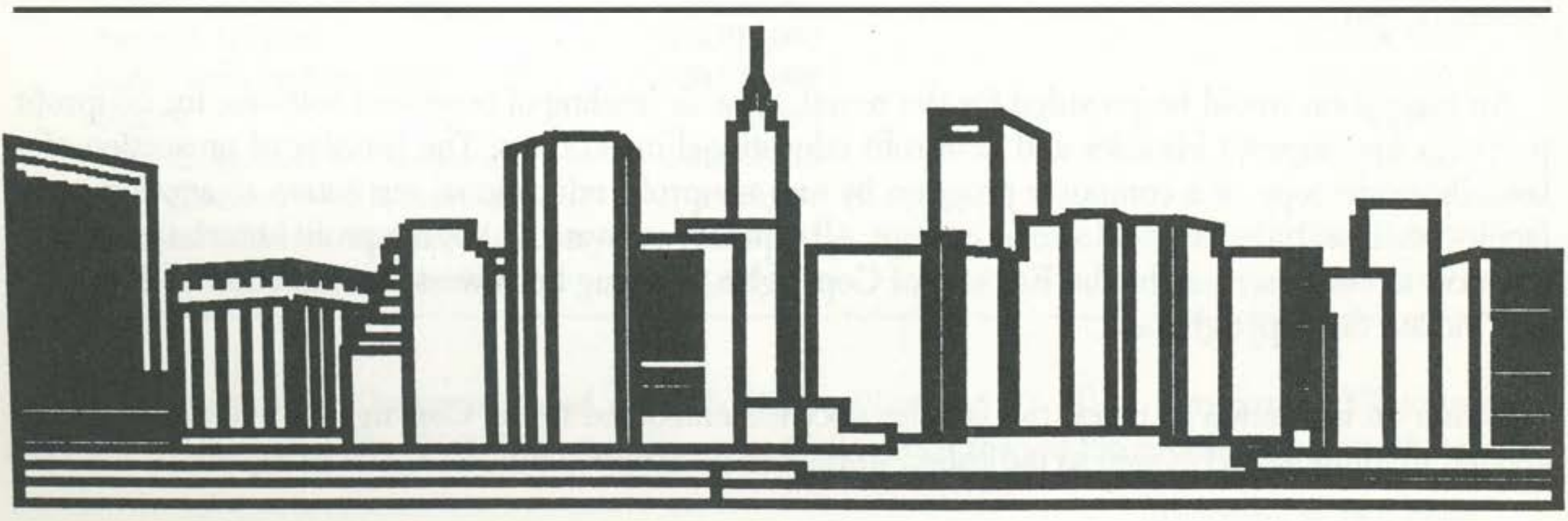

